\title{
Aprocitentan, A Dual Endothelin Receptor Antagonist Under Development for the Treatment of Resistant Hypertension
}

\author{
Fabio Angeli (D) - Paolo Verdecchia - Gianpaolo Reboldi
}

Received: May 26, 2021 / Published online: July 12, 2021

(C) The Author(s) 2021
F. Angeli ( $\square)$

Department of Medicine and Surgery, University of Insubria, Varese, Italy

e-mail: angeli.internet@gmail.com

F. Angeli

Department of Medicine and Cardiopulmonary

Rehabilitation, Maugeri Care and Research

Institutes, IRCCS Tradate, Varese, Italy

P. Verdecchia

Fondazione Umbra Cuore e Ipertensione-ONLUS and Division of Cardiology, Hospital S. Maria della Misericordia, Perugia, Italy

\section{G. Reboldi}

Department of Medicine and Centro di Ricerca Clinica e Traslazionale (CERICLET), University of Perugia, Perugia, Italy receptor antagonism), significantly increasing with doses $\geq 25 \mathrm{mg}$. Only minor differences in exposure between healthy females and males, healthy elderly and adult subjects, fed and fasted conditions, and renal function have been observed. Aprocitentan in patients with resistant hypertension is currently under investigation in the PRECISION phase III trial (ClinicalTrials identifier: NCT03541174). Nonetheless, results of pre-clinical data and studies in humans support the potential role of aprocitentan in this clinical setting. The absolute blood pressure (BP) reductions with aprocitentan are in the ranges established as a surrogate for reduction in cardiovascular morbidity in hypertension. Significant changes in BP with aprocitentan are observed within 14 days, and its BP-lowering effects have also been documented with ambulatory BP monitoring. Finally, aprocitentan enhances the BPlowering effects of other antihypertensive drugs, including renin-angiotensin-system blockers. In conclusion, aprocitentan ameliorates the effects of ET- 1 and could potentially reduce $\mathrm{BP}$ and provide broader cardiovascular protection in patients with resistant hypertension. Available data support the hypothesis that this new agent could expand our antihypertensive arsenal in resistant hypertension, making aprocitentan an attractive candidate for further large-scale trials. 
Keywords: Aprocitentan; Endothelin; Resistant hypertension; Blood pressure; Treatment; Efficacy and safety

\section{Key Summary Points}

Endothelin-1 is the most potent endogenous vasoconstrictor currently available and is implicated in the pathogenesis of hypertension.

Aprocitentan, the active metabolite of macitentan, is a potent, orally active, dual endothelin receptor antagonist and represents a potential novel therapy for hypertensive patients.

Aprocitentan enhances the blood pressure-lowering effects of other antihypertensive drugs with additional potential long-term benefits.

Blocking the actions of endothelin-1 by aprocitentan could potentially reduce blood pressure and provide broader cardiovascular protection to patients with resistant hypertension.

\section{INTRODUCTION}

Endothelin-1 (ET-1) regulates vascular tone and blood pressure (BP) and contributes to the pathogenesis of hypertension [1-3]. It is a potent vasoconstrictor peptide that causes neurohormonal and sympathetic activation, hypertensive end-organ damage (including vascular hypertrophy and remodeling), fibrosis, endothelial dysfunction and increased aldosterone synthesis and secretion [4]. Both animal and human model studies have shown that vascular ET-1 expression is increased in hypertension [1-3].

Aprocitentan (ACT-132577; Fig. 1) is a potent, orally active, dual ET receptor antagonist that prevents the binding of ET-1 to both ETA/ETB receptors, with an inhibitory potency ratio of 1:16 [5-7]. It is a member of the class of

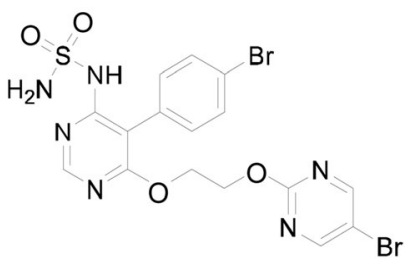

Fig. 1 Chemical structure of aprocitentan

sulfamides in which one of the amino groups of sulfonamide is substituted by a 5-(4-bromophenyl)-6-\{2-[(5-bromopyrimidin-2-

yl)oxy]ethoxy\}pyrimidin-4-yl group [5-7]. Aprocitentan is an active metabolite of macitentan (obtained by oxidative depropylation), an orphan drug used for the treatment of pulmonary arterial hypertension [5-7].

Aprocitentan causes a a dose-dependent decrease in BP and has been shown to have a synergistic effect with renin-angiotensin-system (RAS) blockers. As such, it represents a potential new treatment modality when high BP cannot be adequately controlled by currently available treatments [4].

The main aims of our review were to (1) summarize the pharmacokinetic properties of aprocitentan, (2) analyze the results of clinical studies investigating the safety and efficacy of this drug for the treatment of hypertension and (3) evaluate future directions that could establish the role for aprocitentan in the treatment of resistant hypertension.

For this purpose, literature searches were conducted using PubMed, Scopus, Web of Science, together with the ClinicalTrials.gov database. We selected influential clinical studies in the field of hypertension using research Methodology Filters $[8,9]$. In brief, we used the following search terms: "aprocitentan, endothelin, pharmacology, pharmacokinetics, phaarmacodynamics, hypertension, blood pressure, efficacy and safety". We also performed hand-searching of conference proceedings, pharmaceutical industry files and personal communication from experts in the field, to identify any other relevant study.

No language restriction was applied to the inclusion of articles included in this review.

This article is based on previously conducted studies and does not contain any new studies 
with human participants or animals performed by any of the authors.

\section{ET-1 AND RESISTANT HYPERTENSION}

Endothelin-1 is a 21-amino acid peptide predominantly produced by endothelial cells. Its production by these endothelial cells increases in response to several stimuli, including hypoxia, shear stress, angiotensin II, glucose and inflammatory cytokines [10-12]. It acts in a paracrine manner, producing a powerful vasoconstrictor effect, and exhibits remarkably longlasting actions [2, 3, 13-16]. ET-1 causes endothelial dysfunction and vascular and cardiac remodeling and also contributes to sodium and water regulation in the kidney $[2-4,13,17,18]$. In patients with severe hypertension, ET-1 expression in the endothelium is enhanced, and it plays a role in BP elevation and in the pathogenesis of vascular hypertrophy [14]. The ET system is also upregulated in patients with salt-sensitive hypertension, diabetes, obesity and chronic kidney disease [19]. Experimental models have shown that ET receptor antagonists may prevent and sometimes reverse tissue alterations in an organ-specific manner, leading to long-term benefits [5, 19-21]. It has been also suggested that such benefits may be independent of the hemodynamic effect of therapy [19].

Thus, the involvement of ET system in volume-dependent hypertension, end-organ damage and comorbidities associated with hypertension [19-21] supports the use of the ET-1 receptor antagonist as a new pharmacological strategy in the treatment of resistant hypertension. In addition, although the use of ET receptor antagonists is tempered by a significant adverse side effect profile, including an increase in total body sodium [22, 23], available data show that both selective and mixed antagonists increase forearm vasodilatation and reduce BP in hypertensive patients [24].

The first clinical study in humans to investigate ET antagonism administered the mixed receptor antagonist bosentan as a single agent to patients with mild to moderate primary hypertension [25]. Specifically, 293 patients with mild-to-moderate essential hypertension were randomly assigned to receive one of four oral doses of bosentan $(100,500$ or $1000 \mathrm{mg}$ once daily or $1000 \mathrm{mg}$ twice daily), placebo or a renin-angiotensin-system (RAS) blocker (enalapril $20 \mathrm{mg}$ once daily) for 4 weeks. Compared with placebo, bosentan resulted in a significant reduction in diastolic BP with a daily dose of 500 or $2000 \mathrm{mg}$ (an absolute reduction of $5.7 \mathrm{mmHg}$ at each dose). A similar reduction in diastolic BP was documented between the enalapril $(5.8 \mathrm{~mm} \mathrm{Hg})$ and bosental arms [25].

More recently, a randomized, double-blind, placebo-controlled forced dose-titration study evaluated darusentan (an ET-1 selective antagonist) as an add-on therapy in patients with resistant hypertension [26]. Overall, 115 patients with resistant hypertension who were receiving background therapy with at least three antihypertensive medications, including a diuretic, at full doses were randomized 2:1 to increasing doses of darusentan $(10,50,100,150$ and $300 \mathrm{mg}$ ) or matching placebo once daily for 10 weeks. There was a progressive decline in systolic/diastolic BP throughout the study, with the largest reductions observed at week 10 (300 mg dose: systolic BP reduction $11.5 \mathrm{mmHg}$, diastolic BP reduction $6.3 \mathrm{mmHg}$ ) [26].

Similar results were also obtained by Weber and co-workers in a randomized, double-blind study enrolling 379 patients with resistant hypertension [27].

Conversely, in a clinical trial recruiting 849 patients with resistant hypertension, patients in the darusentan and placebo arms showed a similar decrease in office systolic BP [28]. Due to this negative outcome, further studies into the chronic administration of darusentan in resistant hypertension were terminated.

\section{PHARMACODYNAMIC AND PHARMACOKINETICS}

Aprocitentan is highly bound to plasma proteins and is eliminated in both urine and feces [29]. Single- and multiple-dose tolerability, safety, pharmacokinetics, and 
pharmacodynamics of aprocitentan up to $600 \mathrm{mg}$ (single doses) and $100 \mathrm{mg}$ once a day (multiple doses) have been investigated in healthy male and female subjects [7]. Overall, aprocitentan was well tolerated across all doses. Of note, plasma concentration-time profiles of aprocitentan are similar after single- and multiple-dose administration. Its pharmacokinetic profile shows a half-life of $44 \mathrm{~h}$, fitting a oncedaily dosing regimen with plasma ET-1 concentrations (reflecting ET receptor antagonism), significantly increasing with doses $\geq 25 \mathrm{mg}$. Accumulation at steady state, reached by day 8 , was threefold. Only minor differences in exposure between healthy females and males, healthy elderly and adult subjects, fed and fasted conditions, and renal function were observed [5-7, 29].

Just recently, a double-blind study including 20 healthy male and female subjects showed that pharmacokinetics of aprocitentan did not differ significantly between Japanese and Caucasian patients. Specifically, results documented that maximum plasma concentration was reached at 4 and $3 \mathrm{~h}$, and elimination half-life was 49.1 and $48.8 \mathrm{~h}$ for Japanese and Caucasian subjects, respectively. The accumulation index was around 3 for both populations. Aprociten$\tan$ was safe and well tolerated in both groups [30].

\section{DRUG INTERACTIONS}

Some drug interactions with aprocitentan have been tested (midazolam, rosuvastatin, and RAS blockers) $[4,6,31]$. No significant drug-to-drug interactions have been reported to date.

Trensz and co-workers investigated the pharmacology of aprocitentan on BP and renal function in two models of experimental hypertension (low-renin model and normal-renin model), comparing the effect of its combination with RAS blockers (valsartan and enalapril) with that of the combination of the mineraloreceptor antagonist spironolactone with the same RAS blockers. Briefly, aprocitentan was synergistic with valsartan and enalapril in decreasing BP in both experimental models. Of note, in hypertensive rats under sodium restriction and receiving enalapril, the addition of aprocitentan further decreased the BP without causing renal impairment, in contrast to spironolactone [4].

The drug-drug interaction of aprocitentan and rosuvastatin was investigated in a singlecenter, open-label, single-sequence study. Twenty healthy male subjects received a single dose of $10 \mathrm{mg}$ rosuvastatin on days 1 and 13 followed by pharmacokinetic and tolerability assessments for up to $120 \mathrm{~h}$. From day 5 to day 17 , subjects received $25 \mathrm{mg}$ of aprocitentan once daily. At steady state, aprocitentan did not significantly affect the pharmacokinetics of rosuvastatin, and the combination of rosuvastatin and aprocitentan was well tolerated [31].

Finally, the pharmacokinetics of midazolam in the absence and presence of aprocitentan (loading dose of $150 \mathrm{mg}$ followed by $50 \mathrm{mg}$ once daily) was investigated in 19 healthy male subjects. The pharmacokinetics and tolerability of midazolam and its metabolite 1-hydroxy midazolam were assessed over a 24 -h period after each midazolam administration. At steady state, aprocitentan did not affect the area under the plasma concentration-time curve and the maximum plasma concentration of midazolam and 1-hydroxy midazolam. There were no relevant differences in tolerability parameters between treatments [6].

Of note, the main elimination pathways of aprocitentan are through glucosidation to metabolite M3 by uridine 5'-diphospho-glucuronosyltransferases $1 \mathrm{~A} 1$ and $2 \mathrm{~B} 7$ and mostly chemical hydrolysis to metabolite M1. These pathways are independent of cytochrome P450 enzymes and, consequently, aprocitentan would have limited potential for drug interactions with drugs that induce or inhibit cytochrome P450 enzymes [6, 31].

\section{CLINICAL STUDIES IN HYPERTENSION}

To date, three clinical studies in the setting of hypertension have been registered. The first, PRECISION trial, has the aim to evaluate the BPlowering effect of aprocitentan when added to other antihypertensive drugs in patients with 
Table 1 Main characteristics of the PRECISION trial with the aim to show the effect of aprocitentan in the treatment of difficult to control (resistant) high blood pressure (hypertension) and learn more about its safety

\section{PRECISION trial (ClinicalTrials.gov Description \\ Identifier: NCT03541174)}

Purpose

Evaluate blood pressure-lowering effect of aprocitentan when added to other antihypertensive drugs of patients with resistant hypertension

Design

Multicenter, blinded, randomized, parallel-group, phase 3 study

Allocation: randomized

Intervention model: parallel assignment

Intervention model description:

Single-blind placebo run-in/randomized with 3 parts:

Part 1: double-blind, randomized to aprocitentan $12.5 \mathrm{mg}$, aprocitentan $25 \mathrm{mg}$ or placebo

Part 2: single blind aprocitentan $25 \mathrm{mg}$

Part 3: double-blind re-randomized to aprocitentan $25 \mathrm{mg}$ or placebo

Masking: triple (participant, care provider, investigator)

Estimated enrollment

600 participants treated with at least 3 antihypertensive therapies of different pharmacological classes for at least 4 weeks before the screening visit

Primary outcome measures

Change from baseline to week 4 of double-blind treatment in trough sitting systolic blood pressure

Exclusion criteria

Apparent/pseudo-resistant hypertension

Confirmed severe hypertension

Pregnant or lactating subjects

Clinically significant unstable cardiac disease

Severe renal insufficiency

Any known factor, disease or clinically relevant medical or surgical conditions that, in the opinion of the investigator, might put the subject at risk or interfere with treatment compliance, study conduct or interpretation of the results

Treatment with any medication which may affect blood pressure and/or treatment with high dose of loop diuretics

resistant hypertension; this trial is still recruiting (Table 1).

The second had the purpose to evaluate the BP-lowering effect of aprocitentan when added to the background antihypertensive therapy in patients with uncontrolled BP and chronic kidney disease. Unfortunately, a non-medical decision was made to not initiate this study.

Thus, to date, only a double-blind, parallel study has been completed with the specific aim to evaluate the dose-response of aprocitentan (once-daily oral regimen of 4 doses) on systolic and diastolic BP in participants with grade 1 or 2 
essential hypertension [32]. Participation in this study was planned to last up to 18 weeks. After a single-blind placebo run-in period of 4-6 weeks, participants were randomized to a double-blind treatment period of 8 weeks and a washout and follow-up period ending with an end-of-study visit approximately 12 weeks after randomization. Overall, 490 eligible patients with a sitting diastolic BP of 90-109 $\mathrm{mmHg}$ were randomized to aprocitentan $5,10,25$, or $50 \mathrm{mg}$, placebo or lisinopril $20 \mathrm{mg}$. Briefly, aprocitentan 10, 25 and $50 \mathrm{mg}$ significantly decreased sitting systolic/diastolic unattended office BP from baseline to week 8 (placebo-corrected decreases in systolic/diastolic BP: 7.05/4.93, 9.90/6.99 and $7.58 / 4.95 \mathrm{mmHg}$, respectively), compared with an unattended office BP reduction of 4.84/ $3.81 \mathrm{mmHg}$ with lisinopril $20 \mathrm{mg}$. Protocol control rates at the end of the double-blind treatment period based on sitting systolic $\mathrm{BP}<140 \mathrm{mmHg}$ (mean of 5 measurements with an automatic unattended office BP measurement device) are shown in Fig. 2 [32]. Briefly, control rates ranged from $56.5 \%$ for lisinopril to $69.1 \%$ for aprocitentan $50 \mathrm{mg}$ (1 capsule once daily in the morning) [32]. Of note, the maximum effect was reached at a dose of about $30 \mathrm{mg}$, and half of the effect was reached at a dose of about $10 \mathrm{mg}$, with a plateauing of the dose-response between 25 and $50 \mathrm{mg}$. Furthermore, aprocitentan was not associated with the activation of the neurohumoral system [32]. Interestingly, ambulatory BP monitoring (ABPM) was performed at baseline and at week 8. Systolic and diastolic BP was measured every $20 \mathrm{~min}$ from $06: 00 \mathrm{~h}$ to $23: 00 \mathrm{~h}$ and every $30 \mathrm{~min}$ from $23: 00 \mathrm{~h}$ to $06: 00 \mathrm{~h}$. Compared to placebo, aprocitentan doses of 10, 25, and $50 \mathrm{mg}$ lowered mean 24-h systolic/diastolic BP from baseline by 3.99/4.04, 4.83/5.89 and 3.67/ $4.45 \mathrm{mmHg}$, respectively [32]. Incidence of main adverse events was similar in the aprocitentan groups and the placebo group (Table 2) [32].

\section{CONCLUSION}

Endothelin-1 is the most potent endogenous vasoconstrictor currently known and is

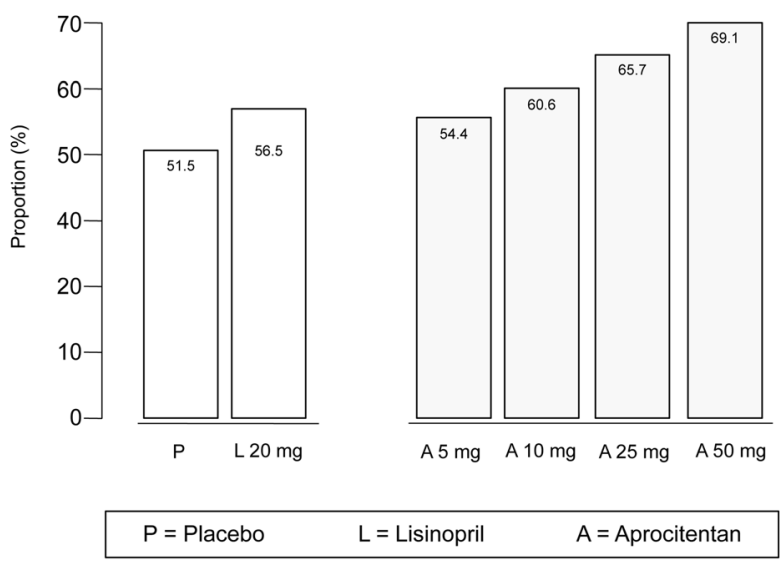

Fig. 2 Control rates at the end of the double-blind treatment period based on systolic blood pressure $<140 \mathrm{mmHg}$ in the dose-finding study with ACT132577 (aprocitentan) in participants with essential hypertension. All participants who had diastolic and systolic blood pressure measurements at week 8 of the double-blind treatment period and who did not have any major protocol deviation were included in the analysis. Data was extracted from [32]

implicated in the pathogenesis of hypertension $[2,3,13,17,18]$. In addition, ET-1 overexpression in the endothelium may contribute to severe BP elevation [14].

ET-1 is involved in the pathogenesis of endothelial dysfunction, promoting the development and progression of resistant hypertension [33]. Indeed, endothelial dysfunction is associated with a shift toward reduced vasodilation, is recognized to be a key early determinant in progression to atherosclerosis, and is now well established as being independently associated with increased arterial stiffness $[33,34]$. Experimental models clearly support the role of ET-1 in the pathogenesis of endothelial dysfunction demonstrating that antagonism of the ET system improves nitric oxide-mediated endothelial function [35-37].

In this context, treatment with ET-1 receptor antagonists may offer a novel therapy for hypertensive patients.

Following the conflicting results on BP lowering [28] and potential adverse effects (fluid retention) [38] obtained with other ET-1 receptor antagonists, aprocitentan in patients with resistant hypertension is currently under 
Table 2 Main adverse events recorded in the dose-finding study with ACT-132577 (aprocitentan) in participants with essential hypertension

\begin{tabular}{|c|c|c|c|c|c|c|}
\hline Event & $\begin{array}{l}\text { Placebo, } \\
\text { affected/at } \\
\text { risk }(\%)\end{array}$ & $\begin{array}{l}\text { Aprocitenten } \\
5 \mathrm{mg} \text {, } \\
\text { affected/at } \\
\text { risk (\%) }\end{array}$ & $\begin{array}{l}\text { Aprocitenten } \\
10 \mathrm{mg} \text {, } \\
\text { affected/at } \\
\text { risk (\%) }\end{array}$ & $\begin{array}{l}\text { Aprocitenten } \\
25 \mathrm{mg} \text {, } \\
\text { affected/at } \\
\text { risk (\%) }\end{array}$ & $\begin{array}{l}\text { Aprocitenten } \\
50 \mathrm{mg} \text {, } \\
\text { affected/at } \\
\text { risk (\%) }\end{array}$ & $\begin{array}{l}\text { Lisinopril } 20 \\
\mathrm{mg} \text {, affected/ } \\
\text { at risk (\%) }\end{array}$ \\
\hline \multicolumn{7}{|l|}{ Cardiac disorders } \\
\hline LBBB & $0 / 82(0.00 \%)$ & $0 / 82(0.00 \%)$ & $0 / 82(0.00 \%)$ & $1 / 82(1.22 \%)$ & $0 / 81(0.00 \%)$ & $0 / 81(0.00 \%)$ \\
\hline $\begin{array}{l}\text { Atrioventricular } \\
\text { block first } \\
\text { degree }\end{array}$ & $0 / 82(0.00 \%)$ & $1 / 82(1.22 \%)$ & $0 / 82(0.00 \%)$ & $1 / 82(1.22 \%)$ & $0 / 81(0.00 \%)$ & $0 / 81(0.00 \%)$ \\
\hline Tachycardia & $0 / 82(0.00 \%)$ & $0 / 82(0.00 \%)$ & $0 / 82(0.00 \%)$ & $1 / 82(1.22 \%)$ & $0 / 81(0.00 \%)$ & $1 / 81(1.23 \%)$ \\
\hline Fall & $0 / 82(0.00 \%)$ & $0 / 82(0.00 \%)$ & $0 / 82(0.00 \%)$ & $0 / 82(0.00 \%)$ & $0 / 81(0.00 \%)$ & $1 / 81(1.23 \%)$ \\
\hline Jaw fracture & $0 / 82(0.00 \%)$ & $0 / 82(0.00 \%)$ & $0 / 82(0.00 \%)$ & $0 / 82(0.00 \%)$ & $0 / 81(0.00 \%)$ & $1 / 81(1.23 \%)$ \\
\hline $\begin{array}{l}\text { Neoplasm } \\
\text { malignant }\end{array}$ & $0 / 82(0.00 \%)$ & $0 / 82(0.00 \%)$ & $0 / 82(0.00 \%)$ & $1 / 82(1.22 \%)$ & $0 / 81(0.00 \%)$ & $0 / 81(0.00 \%)$ \\
\hline Anemia & $0 / 82(0.00 \%)$ & $0 / 82(0.00 \%)$ & $0 / 82(0.00 \%)$ & $2 / 82(2.44 \%)$ & $1 / 81(1.23 \%)$ & $0 / 81(0.00 \%)$ \\
\hline Hyperthyroidism & $0 / 82(0.00 \%)$ & $0 / 82(0.00 \%)$ & $1 / 82(1.22 \%)$ & $0 / 82(0.00 \%)$ & $0 / 81(0.00 \%)$ & $0 / 81(0.00 \%)$ \\
\hline Dyspepsia & $0 / 82(0.00 \%)$ & $0 / 82(0.00 \%)$ & $0 / 82(0.00 \%)$ & $1 / 82(1.22 \%)$ & $0 / 81(0.00 \%)$ & $0 / 81(0.00 \%)$ \\
\hline $\begin{array}{l}\text { Abnormal hepatic } \\
\text { function }\end{array}$ & $0 / 82(0.00 \%)$ & $1 / 82(1.22 \%)$ & $0 / 82(0.00 \%)$ & $0 / 82(0.00 \%)$ & $0 / 81(0.00 \%)$ & $0 / 81(0.00 \%)$ \\
\hline Headache & $1 / 82(1.22 \%)$ & $1 / 82(1.22 \%)$ & $2 / 82(2.44 \%)$ & $2 / 82(2.44 \%)$ & $2 / 81(2.47 \%)$ & $4 / 81(4.94 \%)$ \\
\hline Renal failure & $0 / 82(0.00 \%)$ & $0 / 82(0.00 \%)$ & 0/82 (0.00\%) & $0 / 82(0.00 \%)$ & $0 / 81(0.00 \%)$ & $1 / 81(1.23 \%)$ \\
\hline
\end{tabular}

Data were extracted from [29]

$\angle B B B$ left bundle branch block

investigation in the PRECISION phase III trial (ClinicalTrials identifier: NCT03541174).

To date, the potential role of aprocitentan in this clinical setting is supported by some findings from experimental and clinical studies. First, the absolute reductions in BP achieved with aprocitentan [32] are in the ranges established as a surrogate for reduction in cardiovascular morbidity in hypertension [39-43]. Second, significant changes in BP with aprocitentan are obtained within 14 days [32]. Third, BP-lowering effects of aprocitentan have also been documented with ABPM [32] which is more closely related to target organ damage and cardiovascular outcome than office measurements [44-47]. Finally, aprocitentan enhances the BP-lowering effects of other antihypertensive drugs, including RAS blockers [4].

In conclusion, blocking the actions of ET-1 by aprocitentan could potentially reduce BP and provide broader cardiovascular protection to patients with resistant hypertension. Moreover, this antihypertensive agent could exert additional mechanisms beyond the expected beneficial effects of a sustained BP-lowering action, including a decrease in renal vascular resistance and left ventricular hypertrophy [4]. Taken together, these results support the hypothesis that this new agent could expand our antihypertensive arsenal in resistant hypertension, 
making aprocitentan an attractive candidate for further large-scale trials.

\section{ACKNOWLEDGEMENTS}

Authorship. All named authors meet the International Committee of Medical Journal Editors (ICMJE) criteria for authorship for this article, take responsibility for the integrity of the work as a whole, and have given their approval for this version to be published.

Author Contributions. All authors contributed to the study conception and design, material preparation, data collection and analysis. All authors read and approved the final manuscript.

Funding. No funding or sponsorship was received for this study or publication of this article.

Disclosures. Paolo Verdecchia and Gianpaolo Reboldi have no relationships with the Journal/nothing to disclose. Fabio Angeli is a member of the Editorial Board of the Journal.

Compliance with ethics guidelines. This article is based on previously conducted studies and does not contain any new studies with human participants or animals performed by any of the authors.

Data Availability. Data sharing is not applicable to this article as no datasets were generated or analyzed during the current study.

Open Access. This article is licensed under a Creative Commons Attribution-NonCommercial 4.0 International License, which permits any non-commercial use, sharing, adaptation, distribution and reproduction in any medium or format, as long as you give appropriate credit to the original author(s) and the source, provide a link to the Creative Commons licence, and indicate if changes were made. The images or other third party material in this article are included in the article's Creative Commons licence, unless indicated otherwise in a credit line to the material. If material is not included in the article's Creative Commons licence and your intended use is not permitted by statutory regulation or exceeds the permitted use, you will need to obtain permission directly from the copyright holder. To view a copy of this licence, visit http://creativecommons.org/licenses/by$\mathrm{nc} / 4.0 /$.

\section{REFERENCES}

1. Ergul S, Parish DC, Puett D, Ergul A. Racial differences in plasma endothelin-1 concentrations in individuals with essential hypertension. Hypertension. 1996;28:652-5.

2. Schiffrin EL. Endothelin and endothelin antagonists in hypertension. J Hypertens. 1998;16:1891-5.

3. Schiffrin EL. Endothelin: role in hypertension. Biol Res. 1998;31:199-208.

4. Trensz F, Bortolamiol C, Kramberg M, et al. Pharmacological characterization of aprocitentan, a dual endothelin receptor antagonist, alone and in combination with blockers of the renin angiotensin system, in two models of experimental hypertension. J Pharmacol Exp Ther. 2019;368:462-73.

5. Iglarz M, Binkert C, Morrison K, et al. Pharmacology of macitentan, an orally active tissue-targeting dual endothelin receptor antagonist. J Pharmacol Exp Ther. 2008;327:736-45.

6. Sidharta PN, Dingemanse J. Effect of multiple-dose aprocitentan administration on the pharmacokinetics of midazolam in healthy male subjects. Eur J Drug Metab Pharmacokinet. 2020;45:227-34.

7. Sidharta PN, Melchior M, Kankam MK, Dingemanse J. Single- and multiple-dose tolerability, safety, pharmacokinetics, and pharmacodynamics of the dual endothelin receptor antagonist aprocitentan in healthy adult and elderly subjects. Drug Des Dev Ther. 2019;13:949-64.

8. Haynes RB, Kastner M, Wilczynski NL, Hedges T. Developing optimal search strategies for detecting clinically sound and relevant causation studies in embase. BMC Med Inform Decis Mak. 2005;5:8.

9. McAuley L, Pham B, Tugwell P, Moher D. Does the inclusion of grey literature influence estimates of intervention effectiveness reported in meta-analyses? Lancet. 2000;356:1228-31. 
10. Attina $\mathrm{T}$, Camidge $\mathrm{R}$, Newby DE, Webb DJ. Endothelin antagonism in pulmonary hypertension, heart failure, and beyond. Heart. 2005;91: 825-31.

11. Moorhouse RC, Webb DJ, Kluth DC, Dhaun N. Endothelin antagonism and its role in the treatment of hypertension. Curr Hypertens Rep. 2013;15:489-96.

12. Ruschitzka F, Quaschning T, Noll G, et al. Endothelin 1 type a receptor antagonism prevents vascular dysfunction and hypertension induced by 11beta-hydroxysteroid dehydrogenase inhibition: role of nitric oxide. Circulation. 2001;103:3129-35.

13. Sharifi AM, Schiffrin EL. Endothelin receptors mediating vasoconstriction in rat pressurized small arteries. Can J Physiol Pharmacol. 1996;74:934-9.

14. Schiffrin EL, Deng LY, Sventek P, Day R. Enhanced expression of endothelin-1 gene in resistance arteries in severe human essential hypertension. J Hypertens. 1997;15:57-63.

15. Schiffrin EL, Lariviere R, Li JS, Sventek P. Enhanced expression of the endothelin-1 gene in blood vessels of doca-salt hypertensive rats: correlation with vascular structure. J Vasc Res. 1996;33:235-48.

16. Schiffrin EL, Lariviere R, Li JS, Sventek P, Touyz RM. Enhanced expression of endothelin-1 gene may cause blood pressure-independent vascular hypertrophy. J Cardiovasc Pharmacol. 1995;26(Suppl 3): S5-8.

17. Yanagisawa M, Kurihara H, Kimura S, et al. A novel potent vasoconstrictor peptide produced by vascular endothelial cells. Nature. 1988;332:411-5.

18. Rautureau Y, Schiffrin EL. Endothelin in hypertension: an update. Curr Opin Nephrol Hypertens. 2012;21:128-36.

19. Iglarz M, Clozel $M$. At the heart of tissue: endothelin system and end-organ damage. Clin Sci. 2010;119:453-63.

20. Belaidi E, Joyeux-Faure M, Ribuot C, Launois SH, Levy P, Godin-Ribuot D. Major role for hypoxia inducible factor- 1 and the endothelin system in promoting myocardial infarction and hypertension in an animal model of obstructive sleep apnea. J Am Coll Cardiol. 2009;53:1309-17.

21. Sen S, Chen S, Feng B, Iglarz M, Chakrabarti S. Renal, retinal and cardiac changes in type 2 diabetes are attenuated by macitentan, a dual endothelin receptor antagonist. Life Sci. 2012;91: 658-68.
22. Moore R, Linas S. Endothelin antagonists and resistant hypertension in chronic kidney disease. Curr Opin Nephrol Hypertens. 2010;19:432-6.

23. Gueneau de Mussy P, Sidharta PN, Wuerzner G, et al. Effects of the dual endothelin receptor antagonist aprocitentan on body weight and fluid homeostasis in healthy subjects on a high sodium diet. Clin Pharmacol Ther. 2020;109:746-53.

24. Cardillo C, Kilcoyne CM, Waclawiw M, Cannon RO 3rd, Panza JA. Role of endothelin in the increased vascular tone of patients with essential hypertension. Hypertension. 1999;33:753-8.

25. Krum H, Viskoper RJ, Lacourciere Y, Budde M, Charlon V. The effect of an endothelin-receptor antagonist, bosentan, on blood pressure in patients with essential hypertension. Bosentan hypertension investigators. N Engl J Med. 1998;338:784-90.

26. Black HR, Bakris GL, Weber MA, et al. Efficacy and safety of darusentan in patients with resistant hypertension: results from a randomized, doubleblind, placebo-controlled dose-ranging study. J Clin Hypertens (Greenwich). 2007;9:760-9.

27. Weber MA, Black H, Bakris G, et al. A selective endothelin-receptor antagonist to reduce blood pressure in patients with treatment-resistant hypertension: a randomised, double-blind, placebocontrolled trial. Lancet. 2009;374:1423-31.

28. Bakris GL, Lindholm LH, Black HR, et al. Divergent results using clinic and ambulatory blood pressures: report of a darusentan-resistant hypertension trial. Hypertension. 2010;56:824-30.

29. Sidharta PN, Ulc I, Dingemanse J. Single-dose pharmacokinetics and tolerability of aprocitentan, a dual endothelin receptor antagonist, in subjects with severe renal function impairment. Clin Drug Investig. 2019;39:1117-23.

30. Fontes MSC, Dingemanse J, Sidharta PN. Multipledose pharmacokinetics, safety, and tolerability of aprocitentan, a dual endothelin receptor antagonist, in healthy Japanese and Caucasian subjects. Clin Pharmacol Drug Dev 2020. https://doi.org/10. 1002/cpdd.881.

31. Sidharta PN, Dingemanse J. Effects of multiple-dose administration of aprocitentan on the pharmacokinetics of rosuvastatin. Clin Pharmacol Drug Dev. 2020;9:995-1002.

32. Verweij P, Danaietash P, Flamion B, Menard J, Bellet M. Randomized dose-response study of the new dual endothelin receptor antagonist aprocitentan in hypertension. Hypertension. 2020;75:956-65. 
33. Amiri F, Virdis A, Neves MF, et al. Endotheliumrestricted overexpression of human endothelin-1 causes vascular remodeling and endothelial dysfunction. Circulation. 2004;110:2233-40.

34. Dhaun N, Goddard J, Kohan DE, Pollock DM, Schiffrin EL, Webb DJ. Role of endothelin-1 in clinical hypertension: 20 years on. Hypertension. 2008;52:452-9.

35. Barton M, Haudenschild CC, d'Uscio LV, Shaw S, Munter K, Luscher TF. Endothelin ETA receptor blockade restores no-mediated endothelial function and inhibits atherosclerosis in apolipoprotein e-deficient mice. Proc Natl Acad Sci USA. 1998;95: 14367-72.

36. Bauersachs J, Fraccarollo D, Galuppo P, Widder J, Ertl G. Endothelin-receptor blockade improves endothelial vasomotor dysfunction in heart failure. Cardiovasc Res. 2000;47:142-9.

37. Best PJ, McKenna CJ, Hasdai D, Holmes DR Jr, Lerman A. Chronic endothelin receptor antagonism preserves coronary endothelial function in experimental hypercholesterolemia. Circulation. 1999;99:1747-52.

38. Kohan DE, Pollock DM. Endothelin antagonists for diabetic and non-diabetic chronic kidney disease. Br J Clin Pharmacol. 2013;76:573-9.

39. Angeli F, Verdecchia P, Reboldi GP, et al. Calcium channel blockade to prevent stroke in hypertension: a meta-analysis of 13 studies with 103,793 subjects. Am J Hypertens. 2004;17:817-22.

40. Angeli F, Verdecchia P, Reboldi GP, et al. Metaanalysis of effectiveness or lack thereof of angiotensin-converting enzyme inhibitors for prevention of heart failure in patients with systemic hypertension. Am J Cardiol. 2004;93:240-3.

41. Reboldi G, Angeli F, Cavallini C, Gentile G, Mancia $\mathrm{G}$, Verdecchia P. Comparison between angiotensinconverting enzyme inhibitors and angiotensin receptor blockers on the risk of myocardial infarction, stroke and death: a meta-analysis. J Hypertens. 2008;26:1282-9.

42. Reboldi G, Gentile G, Angeli F, Ambrosio G, Mancia G, Verdecchia P. Effects of intensive blood pressure reduction on myocardial infarction and stroke in diabetes: a meta-analysis in 73,913 patients. J Hypertens. 2011;29:1253-69.

43. Verdecchia P, Angeli F, Cavallini C, et al. Blood pressure reduction and renin-angiotensin system inhibition for prevention of congestive heart failure: a meta-analysis. Eur Heart J. 2009;30:679-88.

44. Angeli F, Gentile G, Trapasso M, Verdecchia P, Reboldi G. Role and prognostic value of individual ambulatory blood pressure components in chronic kidney disease. J Hum Hypertens. 2018;32:625-32.

45. Angeli F, Reboldi G, Poltronieri C, et al. Clinical utility of ambulatory blood pressure monitoring in the management of hypertension. Expert Rev Cardiovasc Ther. 2014;12:623-34.

46. Angeli F, Reboldi G, Verdecchia P. Interpretation of ambulatory blood pressure profile: a prognostic approach for clinical practice. J Hypertens. 2015;33: 454-7.

47. Angeli F, Verdecchia P, Poltronieri C, et al. Ambulatory blood pressure monitoring in the elderly: features and perspectives. Nutr Metab Cardiovasc Dis. 2014;24:1052-6. 